\title{
DEMOGRAPHIC RISK FACTORS FOR SEVERE DISEASE IN PULMONARY TUBERCULOSIS
}

\author{
Balachandran J11, Baiju Sam Jacob²
}

\section{HOW TO CITE THIS ARTICLE:}

Balachandran J, Baiju Sam Jacob. "Demographic Risk Factors for Severe Disease in Pulmonary Tuberculosis". Journal of Evolution of Medical and Dental Sciences 2014; Vol. 3, Issue 14, April 07; Page: 3673-3678, DOI: $10.14260 /$ jemds/2014/2341

\begin{abstract}
Tuberculosis is a major public health problem. Some patients present with minimal lesions where as others present with advanced lesions. This is a Case control study to identify the strength of associations between various demographic risk factors like age, residence, socioeconomic status and educational status and severity of disease. There were 80 cases and 80 controls. The study was done over a period of 18 months. Severity of tuberculosis was assessed by chest radiographic criteria as per American Thoracic Society recommendation. Older age group had higher risk for the development of severe pulmonary tuberculosis compared to younger patients. 78.5\% of patients with severe disease were residing in rural areas whereas it was $43.75 \%$ in the control group. $75 \%$ of patients with severe disease belonged to lower socio-economic status whereas it was $57.5 \%$ in the case of patients with minimal disease. Illiterate people constituted $80 \%$ of patients with severe disease but 57.5\% in case of mild disease. Both univariate and multivariate analysis were done. Age was found to be independent risk factors for the development of severe forms of pulmonary tuberculosis. But when residence, socio-economic status and educational status were analyzed together by multivariate method, only residence (rural) was found to be a risk factor. Thus elderly people and those residing in rural areas have higher risk to develop severe pulmonary tuberculosis. Therefore preventive measures may be targeted to these groups.
\end{abstract}

KEYWORDS: Pulmonary tuberculosis, severe disease, demographic risk factors.

INTRODUCTION: Tuberculosis continues as a significant cause of morbidity and mortality especially of the developing world. ${ }^{1}$ Most commonly, in about $90 \%$ of cases ${ }^{2}$, the disease involves the lungs. The development of pulmonary tuberculosis from its onset to its various clinical manifestations may be pictured as a series of battles between host and invader. The inhaled bacillus may multiply or it may be eliminated by alveolar macrophages before any lesion is produced. The interplay between the multiplication of the bacilli and the response of the host to their components determine whether the infection will progress or regress, and if it does progress, what form will it take. ${ }^{3}$

Tuberculosis is a local disease in that each lesion is handled by the host almost as if other lesions do not exist. Thus lesions in one area may progress, while those in other areas may stabilize or even regress. ${ }^{4}$ The liquefaction of caseous foci perpetuates pulmonary tuberculosis among the human population because it results in cavity formation.

A cavity is formed when a caseous focus ruptures through the wall of a nearby bronchus and discharges its contents into the air passages. The extent of the disease is determined by the number of bacilli and their viability in addition to the amount of aspiration of liquefied caseous material through the bronchial tree. ${ }^{5}$ Tuberculosis is a granulomatous disease. Granuloma formation is due to delayed type hypersensitivity. Thus the host could overcome the reinfection/reactivation much more rapidly than it overcame the primary infection. But the delayed type hypersensitivity is not always 


\section{ORIGINAL ARTICLE}

beneficial. Such hypersensitivity is responsible for the tissue injury that occurs when the concentrations of bacilli and their products are high. ${ }^{6}$

The effects of ageing on the lungs' defense mechanisms are related to pulmonary disease of the elderly.7,8 Various epidemiological studies indicate that nutritional factors play a role in the incidence of tuberculosis particularly of the severe type. ${ }^{9}$ Factors which can predispose to reactivation of quiescent lesions include poor living conditions. ${ }^{10}$

Lower socio-economic status has also been found to affect adversely. ${ }^{11}$ This study was undertaken to find out any demographic risk factors like age, residence, socio-economic factors and educational status, which lead to the development of severe forms of pulmonary tuberculosis.

MATERIALS AND METHODS: Patients admitted in the wards of the Department of Pulmonary Medicine, Medical College, Trivandrum as well as in the wards of the Health services department, Pulayanarkottah Hospital, Trivandrum, who satisfied the inclusion and exclusion criteria were selected as cases. Controls were selected from patients attending the state TB centre, Trivandrum, satisfying the inclusion and exclusion criteria.

\section{Inclusion criteria for cases:}

1. Sputum AFB positivity

2. "Far advanced lesions" in the chest x-ray as per ATS criteria

\section{Inclusion criteria for controls:}

1. Sputum AFB positivity

2. "Minimal lesions" in the chest x-ray as per ATS criteria

\section{Exclusion criteria:}

1. History of Anti TB treatment for more than 10 days

2. Presence of radiological lesions in a previous radiograph, if available

The sample size was estimated to be 72 . Assuming an attrition rate of $10 \%, 80$ patients were included in the study as cases and 80 patients as controls.

The study was completed by 18 months.

The socio-economic groups were formed as per Manual of Economic status scale 1962 by Kuppuswamy B, revised by Narayan Rao S "The Economic status scale" published in 1973. Scores were given for Occupation ( 1 to 10 ), Income (1 to 10) and other factors like owning a house, car, motorbike etc. and the total scores were used for the classification as follows:

Upper socio-economic class 26-29

Middle socio-economic class $\quad 11-25$

Lower socio-economic class $\quad$ Below 11

\section{OBSERVATIONS:}

\begin{tabular}{|c|c|c|c|c|c|}
\hline SL. No. & Sex & Cases & $\%$ of total & Controls & $\%$ of total \\
\hline 1 & Males & 64 & 80 & 60 & 75 \\
\hline 2 & Females & 16 & 20 & 20 & 25 \\
\hline & Total & 80 & 100 & 80 & 100 \\
\hline
\end{tabular}




\section{ORIGINAL ARTICLE}

\begin{tabular}{|c|c|c|c|c|c|}
\hline SL. No. & Residence & Cases & \% of total & Controls & \% of total \\
\hline 1 & Urban & 17 & 21.25 & 45 & 56.25 \\
\hline 2 & Rural & 63 & 78.75 & 35 & 43.75 \\
\hline & Total & $\mathbf{8 0}$ & $\mathbf{1 0 0}$ & $\mathbf{8 0}$ & $\mathbf{1 0 0}$ \\
\hline
\end{tabular}

Table 2: Residence of study population

\begin{tabular}{|c|c|c|c|c|c|}
\hline SL. No. & Economic status & Cases & \% of total & Controls & \% of total \\
\hline 1 & Middle & 20 & 25 & 36 & 42.5 \\
\hline 2 & Lower & 60 & 75 & 44 & 57.5 \\
\hline & Total & $\mathbf{8 0}$ & $\mathbf{1 0 0}$ & $\mathbf{8 0}$ & $\mathbf{1 0 0}$ \\
\hline
\end{tabular}

Table 3: Economic status of study population

\begin{tabular}{|c|c|c|c|c|c|}
\hline SL. No. & Educational status & Cases & \% of total & Controls & \% of total \\
\hline 1 & Literate & 16 & 20 & 34 & 42.5 \\
\hline 2 & Illiterate & 64 & 80 & 46 & 57.5 \\
\hline & Total & $\mathbf{8 0}$ & $\mathbf{1 0 0}$ & $\mathbf{8 0}$ & $\mathbf{1 0 0}$ \\
\hline
\end{tabular}

Table 4: Educational status of study population

\section{ANALYSIS OF RESULTS:}

\begin{tabular}{|c|c|c|c|c|c|c|c|}
\hline Cut off Point & Co eff. & S.E. & Z-score & p-value & O.R. & Lower & Upper \\
\hline $50-50$ & 0.7687 & 0.3365 & 2.2848 & 0.0223 & 2.157 & 1.115 & 4.171 \\
\hline $40-50$ & 0.9976 & 0.3314 & 3.0105 & 0.0026 & 2.712 & 1.416 & 5.192 \\
\hline $30-50$ & 1.0601 & 0.3924 & 2.7020 & 0.0069 & 2.887 & 1.338 & 6.229 \\
\hline
\end{tabular}

Table 5: Relative risk of Age in severe disease compared to minimal disease

A cut off point was fixed and the risk for those aged above this was compared with those below this point. With cut-off point of 50-50, 40-50 and 30-50, the older age group had higher risk compared to the younger group. The Odds ratio was above 2 in all the cases and p value less than 0.05

\begin{tabular}{|c|c|c|c|c|c|c|}
\hline Co eff. & S.E. & Z-score & p-value & O.R. & Upper & Lower \\
\hline 0.2877 & 0.3805 & 0.7560 & 0.4496 & 1.333 & 0.632 & 2.811 \\
\hline
\end{tabular}

Table 6: Relative risk of male sex in severe disease compared to minimal disease

Sex was not found to be a risk factor nor was it found to be a protective one. 


\section{ORIGINAL ARTICLE}

\begin{tabular}{|l|c|c|c|c|c|c|c|}
\hline \multicolumn{1}{|c|}{ Ref category } & Co eff. & S.E. & Z-score & p-value & O.R. & Lower & Upper \\
\hline Residence & -2.0545 & .4825 & -4.2676 & .0000 & .128 & .050 & .330 \\
\hline Soc.Ec.st. & -0.8979 & .3423 & -2.6232 & .0087 & .407 & .208 & .797 \\
\hline Edu. stat. & -1.0840 & .3595 & -3.0149 & .0026 & .338 & .167 & .684 \\
\hline
\end{tabular}

Table 7: Protective effect of residence (urban), economic status (upper) and educational status (literacy) in the development of severe disease compared to minimal disease

Patients residing in urban areas, those with comparatively higher socio-economic status and those who are literate are found to have lesser incidence of far advanced pulmonary tuberculosis than those residing in rural areas, those of lower socio-economic status and the illiterate respectively.

\begin{tabular}{|l|c|c|c|c|c|c|c|}
\hline \multicolumn{1}{|c|}{ Term } & Co eff. & S.E. & Z-score & p-value & O.R. & Lower & Upper \\
\hline Edu.st & .4116 & .4088 & 1.4391 & .1501 & 1.802 & .808 & 4.032 \\
\hline Soc.Eco.st & .3863 & .3618 & 1.0678 & .2856 & 1.471 & .724 & 2.990 \\
\hline Residence & .9521 & .2320 & 4.1042 & .0000 & 2.591 & 1.644 & 4.083 \\
\hline
\end{tabular}

Table 9: Relative risk of Educational status, Socio-economic status and Residence when these three variables are considered together

When the three variables - Educational status, Socio-economic status and Residence were analyzed together, only residence (rural) was found to be a significant risk factor.

\begin{tabular}{|c|c|c|c|c|c|c|c|}
\hline Term & Co eff. & S.E. & Z-score & p-value & O.R. & Lower & Upper \\
\hline Age & .0364 & .0119 & 3.0534 & .0023 & 1.037 & 1.013 & 1.062 \\
\hline Sex & .0368 & .4011 & .0917 & .9269 & 1.031 & .473 & 2.277 \\
\hline
\end{tabular}

Table 10: Relative risk of Age and Sex when these two variables were considered together

Age is a significant risk factor whereas sex is not so.

\begin{tabular}{|c|c|c|c|c|c|c|c|}
\hline Term & Co eff. & S.E. & Z-score & p-value & O.R. & Lower & Upper \\
\hline Age & .0330 & .0120 & 2.7481 & .0060 & 1.034 & 1.010 & 1.058 \\
\hline Soc. Ec. & .5284 & .3253 & 1.6241 & .1043 & 1.696 & .896 & 3.209 \\
\hline
\end{tabular}

Table 11: Relative risks of Age and Lower socio-economic status when these two variables are considered together

Socio-economic status is not found to be a risk factor when age was also considered.

DISCUSSION: Pulmonary tuberculosis is characterized by cavity formation especially in its severe forms of the disease. If extensive and bilateral, these increase the mortality and morbidity of the host. In addition the disease also becomes more infectious and hence the significance of these severe forms of pulmonary tuberculosis. The gold standard of diagnosis of pulmonary tuberculosis is sputum examination for acid fast bacilli.2,12

The severity is assessed by radiological criteria as per ATS recommendation. ${ }^{13}$ Why some patients present with severe forms of pulmonary tuberculosis has not clearly been answered. Most of 


\section{ORIGINAL ARTICLE}

studies point to the risk of development of tuberculous infection and disease and not on severity. ${ }^{9-11}$ The present study identifies some demographic risk factors which lead to severe forms of pulmonary tuberculosis. The data was analyzed and multiple logistic regression was performed by unconditional and conditional methods. Univariate analysis was done first and Z-score as well as Odds Ratio were calculated for each variable. In the multivariate analysis, two or more variables were analyzed together. The confounding effect of one variable over another was also looked for.

Univariate Analysis: Older age group (above 50 years) was found to be a significant risk factor in causing severe pulmonary tuberculosis (p-value less than 0.05) Sex was not found to be a risk factor nor was it found to be a protective one. (p-value 0.4496) Patients residing in urban areas and those with comparatively higher socio-economic status were found to have lesser incidence of far advanced lesions than those residing in rural areas and those of lower socio-economic status respectively. (pvalue less than 0.05) Patients who were literate had lesser incidence of severe disease.

Multivariate Analysis: Analysis was done considering more than one variable in each step. This also helped to identify the confounding factors. When economic status and age were analyzed, the former was not found to be a risk factor. This means that the risk as shown by the univariate analysis is, in fact dependent on age. The economic status of older people is definitely lower than that of the younger people. When economic status educational status and residence were analyzed by the multivariate method, it was shown that only residence was a significant risk factor. The increased risk among people residing in the rural area could be due to lack of proper health facilities.

CONCLUSIONS: Certain demographic risk factors were identified in patients with far advanced lesions of pulmonary tuberculosis. They were - Age, Lower socio-economic status, Residence in rural areas and Illiteracy. All the above factors were not directly involved in causing the development of severe disease. Residence in rural areas and increasing age were found to be definite risk factors. Socio-economic status and Educational status were not found to be significant risk factors when the confounding effect of age and rural residence were taken into account. Sex was not found to be a risk factor nor was it found to be a protective one.

Thus, old age and rural residence may be identified as risk factors so that the number of patients with severe forms of the disease will decrease in number leading eventually to improved control of pulmonary tuberculosis. The causes of risk of increased risk in old age could be due to lowering of resistance secondary to decline in the efficiency of immune mechanisms as well as to the loss of ciliary mechanisms leading to impaired drainage of mucus. The increased risk in the lower socio-economic group is likely due to malnutrition which adversely affects the immunity and factors like overcrowding and lack of availability of treatment.

\section{REFERENCES:}

1. World Health Organization (2009). Epidemiology.Global tuberculosis control: epidemiology, strategy, finances. pp. 6-33. Retrieved 12 November 2009.

2. Behera, D. (2010). Textbook of pulmonary medicine (2nd ed.). New Delhi: Jaypee Brothers Medical Pub. p. 457.

3. Dannenberg A M Jr (1984). Pathogenesis of Tuberculosis Microbiology p 344-354. 


\section{ORIGINAL ARTICLE}

4. Salvin S B and Neta R. Relation between Delayed Hypersensitivity and Immunity in Tuberculosis. American Review of Respiratory Disease 1975: (111); 373-377.

5. Kumar V, Abbas AK, Fausto N, Mitchell RN (2007). Robbins Basic Pathology (8th ed.) Saunders Elsevier. pp. 516-522.

6. Grosset J. Mycobacterium tuberculosis in the Extracellular Compartment: an Underestimated Adversary. Antimicrobial Agents and Chemotherapy 2003; 47 (3): 833-836.

7. Erin L. Detection of pulmonary tuberculosis by sputum survey. Tubercle 1960 (41); 363-366.

8. Hebbert F J. Pulmonary tuberculosis. Lancet 1948: (2); 247.

9. Tverdal A. Body mass index and incidence of tuberculosis. Eur J Resp Dis 1986:69(5); 355-362.

10. Finch R G and Cope J R. Unsuspected tuberculosis in general hospitals. Lancet 1973; (1), 1496.

11. Chevallay B, de Haller R and Bernheim J. Epidemiology of pulmonary tuberculosis in the prison environment. New Eng J Med 1983:113(7); 261-265.

12. Jindal SK editor-in-chief (2011). Textbook of pulmonary and critical care medicine. New Delhi: Jaypee Brothers Medical Publishers. p. 544.

13. Diagnostic Standards and Classification of Tuberculosis. American Review of Respiratory Disease Vol. 142, No. 3, Sept 1990 pp. 725-735. American Thoracic Society.

\section{AUTHORS:}

1. Balachandran J.

2. Baiju Sam Jacob

\section{PARTICULARS OF CONTRIBUTORS:}

1. Associate Professor, Department of Pulmonary Medicine, Travancore Medical College, Kollam.

2. Associate Professor, Department of General Medicine, Travancore Medical College, Kollam.

\section{NAME ADDRESS EMAIL ID OF THE} CORRESPONDING AUTHOR:

Dr. Balachandran J,

Associate Professor,

Department of Pulmonary Medicine,

Travancore Medical College,

Kollam - 691589, Kerala.

E-mail: doctorbalachandran@gmail.com

Date of Submission: 03/03/2014.

Date of Peer Review: 04/03/2014.

Date of Acceptance: 21/03/2014.

Date of Publishing: 04/04/2014. 